\title{
Singularity.
}

\section{A manifesto for incomparable geographies}

Tariq Jazeel (UCL)

\section{Library.}

Tayeb Salih's 1969 novel Season of Migration to the North is an inversion of Joseph Conrad's Heart of Darkness (1899 [2007]). The novel's Kurtz figure is Mustafa Sa'eed, a Sudanese man who finds himself in London in the 1950s and sets about seducing, then driving to suicide, a series of English women who harbor Orientalist fantasies about him. Narratively speaking, Sa'eed's actions are the colonial counterpoint to Kurtz's decline into madness in Heart of Darkness and his obsession to 'exterminate all the brutes!' In his reading of Salih's novel, the literary theorist Aamir Mufti (2005) focuses on a brief narrative moment in the text that I want to pose as a backdrop to this paper. After a prison term in England, the novel's Sudanese protagonist Sa'eed returns to Sudan and settles in a village on the banks of the river Nile, where he meets and tells his story to the novel's narrator, who himself has just returned from England with a $\mathrm{PhD}$ in English poetry. Mufti focuses on a moment in the text where the narrator enters a room in Sa'eed's house that has heretofore been kept locked. In an image as cultural as it is political economic, it turns out that the room is a replica of an English study, with Victorian chairs covered in silk, a round table with notebooks on it, a fireplace, oil portraits on the wall, and photographs of Sa'eed arranged on a shelf. But most of all books; books which line the walls everywhere, books that sit on chairs, book on tables, books on the floor. An A-Z of books, covering topics from Astronomy through Zoology, reference works like the Encyclopedia Britannica. Authors from Hardy to Woolf. Philosophers from Moore 
through Wittgenstein. Four volumes by Mustafa Sa'eed himself portentously titled The Economics of Colonialism; Colonialism and Monopoly; The Cross and Gunpowder; and The Rape of Africa. Even the Qur'an and Bible in English. But not a single Arabic book. For the narrator, the room is at once "A prison. A huge joke. A treasure chamber" (Salih 1969, p.138).

This paper is set against the backdrop of Mustafa Sa'eed's Anglophonic and allegorical library. It is a paper that pushes at that jocular ambiguity that makes it difficult to decide whether this library is bountiful with the promise of intellectual treasure or in fact a prison. In so doing, this is a paper that responds quite directly to the theme of the 2017 RGS/IBG annual conference, Decolonizing Geographical Knowledge, specifically by pushing at the process of opening geography to the world announced by the theme's subtitle. I want to suggest that as a discipline, a methodological disposition toward singularity, toward the particular, might well help to facilitate the decolonization of geographical knowledge production. Instead of trusting that we can build an adequate geographical imagination for our reading publics, for our students, and ourselves, with the resources that Sa'eed's library offers us, I argue in this paper that the singular offers us compelling ways of moving the geographical imagination toward alterity. In this sense, I want to propose the singular as an ethical imperative poised to mitigate the possibility of research on southern, subaltern or indigenous contexts becoming a kind of empirical conscript to a theoretical modernity that remains firmly located in the EuroAmerican academy (see Scott 2004). As I suggest, the singular offers a direction of travel poised to puncture the conceit of Sa'eed's library's bountiful but intensely Eurocentric promise of utopian worldliness in the light of the fact that, as Aamir Mufti (2005, p.474) 
extrapolates from his reading, "we are all Eurocentric" now (also see Chakrabarty 2000; Roy 2016).

\section{Comparison.}

Though I use the word manifesto to describe the task of making this argument, I am aware that this is a rather bombastic (which is to say modernist) and imperfect trope for the work that follows, not least because it is central to my argument that there can be no formulaic access to the singular. Instead, the word 'manifesto' intends to mark out a few methodological resources and watchwords germane to the task of decolonizing geographical knowledge via an orientation toward the singular. Equally, the idea of 'a manifesto for incomparable geographies' intentionally gestures to work in urban geography and urban studies on comparison in recent years, though as I make clear I want to take these discussions on comparison in other directions. Over the last ten to fifteen years, urban geographers have been acutely aware of the value and pitfalls of comparative methods for urban research. The field has seen a proliferation of work that, first, critically points to the implicit comparisons when global south cities are framed by an archive of urban theory that has largely emerged from research conducted on a few key cities that have become 'paradigmatic' (Nijman 2000) or 'superlative' (Beauregard 2003): Chicago, Los Angeles, New York, London, Paris, for example. And second, urban geography and urban studies has steadily built a valuable new repertoire of urban knowledge by comparing diverse cities across and between global north and south, rejecting the integrationist modes of comparison that consciously or unconsciously pull all cities into urban studies' unfortunate history of categorization and developmentalism (Robinson 2006; Myers 2014; McFarlane 2010, p.728). The subtitle of this paper should make it clear that the 
notion of singularity I have in mind speaks in relation to this important work. In other words, even though this is not an urban paper per se, it is in the context of urban geography's turns toward comparison and comparativism that it makes sense to delineate singularity as an ethical imperative for decolonizing geographical knowledge.

If this is a paper that departs from this turn toward comparison, it is important to stress that 'a manifesto for incomparable geographies' is not in any way a manifesto against comparison. Indeed, much of the recent scholarship on urban comparison has aimed precisely to bring us face to face with the incomparable. For example, Colin McFarlane (2010, p.739, my emphasis) has been quite clear that his own interrogation of comparison in urban studies moves toward "one possible route through which alternative theories of the urban might emerge." Likewise, Jennifer Robinson (2016a; 2016b) has been consistent and insistent that comparative urbanism is at its most useful when it leads urban studies toward conceptual revision and experimentation. And some of Robinson's (2016b) most recent work has mobilized Deleuzian notions of singularity (to which I return below) precisely as a way of interrogating how urban case studies might productively generate a revisable, and ultimately more global urban studies. If these debates and questions around comparison have proliferated in urban geography in recent years, they have not had as much of an impact on the geographical discipline beyond its specifically urban domains. As such, part of the argument of this paper is that if comparative methods and approaches in urban studies aim at producing a certain kind of ambivalence toward extant urban theorization in the service of its revisability, then geographical research more generally might likewise cultivate something of that same suspicion toward its own archive of 
disciplinary knowledge production. Opening toward singularity demands this kind of ambivalence.

Part of the work of this paper however, is to push the implications of comparative urban scholarship a little further. Specifically, I want to probe the very limits of the revisable idea as urban studies might conceive it. Heuristically, this is to stress two things: First, that in a specifically urban context, that commitment to "revisable urban theory" in the service of a more "global urban studies" (Robinson 2016a, p.187), ends up (necessarily) proscribing that new theorization or concept work inevitably reconstellate around 'the urban' as a universal and taken-as-given knowledge object (Wachsmuth 2014). This much is inevitable given that urban geography and urban studies must retain its focus on its principal knowledge objects, which are of course the city, the urban, and urbanization; there is a certain and indeed necessary inevitability about this (see Jazeel 2018a, p.406). Second though, the paper queries how the very notion of a more "global urban studies" unwittingly also leaves untended the conceptualization of the 'global', or worldly, in comparative thought. It is to this that I turn in the next section, not exclusively via urban studies however, but instead by looking as well to literary studies and its mobilization of comparativism as a methodology for critiquing the globalization of thought.

\section{World.}

Not least from its ability to stand at times for both the earth itself and for what is on earth or indeed in the purview of one individual, the concept of the world has always had a great deal of latitude: it can be at once geographical and intellectual. (Gaston 2013, p.3) 
If part of the work of this paper is to interrogate global claims, or the worldly aspirations contained within Mustafa Sa'eed's Anglophonic library, then it is worth asserting that as much as the world is a material, thingly, biophysical entity, it is also a figure, a concept, that has deep historical roots in the European metaphysical tradition, from Kant's engagement with the Copernican Revolution onwards. As Sean Gaston (2013, p.xi) has written, it is this philosophical and hermeneutic tradition that tethers the concept of world - and by implication, 'the ever more worldly' that decolonization moves toward - to the "all-too ready acceptance of a seemingly unavoidable logic of containment that has its roots in the classical tradition." In a move that seems to build on the critique of this logic of containment, Aamir Mufti's most recent book, which is a critique of the category of 'World Literature', has drawn attention to the ways that the adjectival prefix of 'world' in 'World Literature' functions as a "plane of equivalence, a set of categorical grids and networks that seek, first of all, to render legible as literature a vast and heterogenous range of practices of writing from across the world and across millennia, so as to be able, second, to make them available for comparison, classification, and evaluation" (2016, p.11, emphasis in original). What he stresses, of course, is how the promise of particular worldly, or indeed cosmopolitan, imaginations actually flatten difference, turning it into the comfortable coordinates of diversity because of the sticky particularity of that universal vision (also see Roy 2016, p.206).

Interrogating this problematic notion of global diversity is, of course, very relevant for thinking through a geography of difference in the comparative imagination. Indeed, this is the kind of algorhythmic and computational geographical imagination 
that Gayatri Spivak (2003, p.72) critiques through her methodological trope of planetarity which she proposes to "overwrite the globe". The globe and globalization, for Spivak (ibid.), imply the "imposition of the same system of exchange everywhere"; they are an extension of that containing sense of 'world' in the classical tradition. The globe and globalization present us with an abstract ball covered in the lines of longitude, latitude and other computed lines of measurement and classification through which we can easily compare. The globe is that which GIS and the graticule present to us for immediate comprehensibility. But Spivak's point is that immediate comprehensibility is antithetical to actually existing singularity. For her it is the planet that offers us a way around these reductive comparisons and into the ethico-conceptual space of singularity. The planet is that which slips from the grip of algorhythmic or computational logic; it is that which cannot be fixed by the messianic gaze of one system of measurement with universal pretensions. The planet, as she puts it, "is in the species of alterity" (ibid, p.72). It means such different things to different groups located (dis)continuously across its surface that it continually "flings us away" (ibid., p.73). The key point here is that alterity, as opposed to mere diversity, is underived from us. It is that for which we do not (yet) have a language.

The key thing I want to tease out here is that if it is inevitable that there will always be the kind of planetary difference that resists being known and therefore contained theoretically and conceptually, then planetary difference is a methodological challenge. It is an imperative woven into decolonization that should steer us toward the effort required to grasp differences on terms true to the singularity of those differences. Planetarity is thus a disposition to knowledge, and as Spivak (2013, p.73) writes, "[w]e must persistently educate ourselves into this peculiar mindset." 
Equally, planetarity is a trope for our discipline insofar as it implicates Geography as earth-writing (see Friess and Jazeel 2017). It asserts the always-already multitudinous scriptings or textualizations of multiple worlds. Educating ourselves into the mindset of planetarity therefore, means developing literacies that enable us to read the planet's many and discontinuous textual fabrics. In other words, and unsurprisingly given that both Spivak and Mufti are literary theorists, the world, or planet, for them is textual. It is written. However, and this is a point that has too often been lost in the recent history of debates concerning cultural geography's materialist turns, the planet is not always written in English. That is to say, it is not always written in a script that is easily legible by and to the (Anglophone) geographical researcher. To make this point is, of course, to veer toward an ontological position: 'there is no outside text' / 'il n'y a pas de hors-texte', and so on. However, I would not want to characterize this as an anti-materialist post- or de-colonial position. Indeed, a close reading of Edward Said's Orientalism (1978), and his later collection of essays The World, The Text, and the Critic (1984), reveals how early postcolonial readings of the textuality of (spatial) knowledge never denied materiality, but sought instead to seek understandings of how materials like the world, like space, come to mean in certain kinds of ways. Indeed, this is a point that readers of the Singapore Journal of Tropical Geography will need no reminding of given the spatial ambiguity and discursive history of what we now so readily refer to as 'the tropics'. As Felix Driver and Brenda Yeoh (2000) reminded us in a special issue of this journal some years ago now, as material as tropical space is, its history and that of tropical vision is entirely complicit with colonialism and imperialism. What concerns me in what follows is how to be able to read, to discern 
the outlines of, the other story? Methodologically, how as researchers can we make that move into the text of the other?

To this extent, it is important to stress that the singularities I evoke in this paper are spatial and historical, not temporal. In other words, they are positioned in geographically relational ways to the here and now; to the wellsprings and vanguard of what we consider to be the cutting edge of our disciplinary knowledge production: the RGS/IBG annual conference, our top ranking peer-reviewed journals, so on and so forth. The singularities to which I am gesturing are historical insofar as they have their own relationally connected pasts, but they are also simultaneous with us in the here and now (Massey 2005). This is an important point because it is to position the kind of singularity I evoke here in relation to the patterns of repetition and difference that produce a singularity that Gilles Deleuze (1994) famously opposes to representation. This is a move I do not want to make because of its geographical implications, even though, as Dewsbury and Thrift emphasize, Deleuze's political challenge is to foster a life in which repetitions co-exist "in a space in which difference is distributed" (Deleuze in Dewsbury and Thrift 2005, p.91). For Deleuze, however, it is the immanence of space, its configuration as a "moving concept" (Dewsbury and Thrift 2005, p.89), that places it outside the reach of representation. The point here is that when Deleuze writes of repetition as a "singularity opposed to the general" (1994, p.3), and when he states that "[t]he theatre of repetition is opposed to the theatre of representation, just as movement is opposed to the concept and to representation" (ibid., p.12), it is important to recognize the temporalizing movement forward that he is evoking. This is the event-oriented immanence of Deleuzian spatiality, which seems to not quite be the lateral movement into quite other spatial 
contexts where our literacy fails us. In other words, and to return this reading to the motif with which this paper began, Deleuzian singularity is not the movement out of the quite particular Anglophonic epistemic space of Mustafa Sa'eed's library in Season of Migration to the North; his singularity is not a movement into the Sudanese space that surrounds Sa'eed's library so to speak. It is instead a temporal movement forward that pushes beyond our extant representational capacity. My point is that the singularities to which I am gesturing are not immanent, at least they are not about to be formed as the rhizome produces anew its changing same. The singularities to which I am referring are simultaneous with one another, they are relational too, but they are discontinuous with our conceptual systems. We do not have the language for them, which is not to say these singularities have not yet emerged. They exist, but in radically different epistemic domains. This is what makes them singular and incomparable in the concept world we inhabit.

That said, Deleuze's central problematic regarding the essence of repetition is a useful one insofar as, in his words, the problem "is a question of knowing why repetition cannot be explained by the form of identity in concepts or representations" (1994, p.23). As Jennifer Robinson (2016b, pps.17-18) has written in an astute reading of Deleuzian singularity, "Deleuze draws us into a proliferation of revisable Ideas (and infinite learning; 1994: 241), already intimately connected with many other concepts and experiences but amongst which there is no original model, original or copy (1994: 153)." For my purposes, this is useful inasmuch as we can think that revisability across space contiguous with us, but at the same time epistemically discontinuous. It is the necessary temporal simultaneity and spatial contiguity of this notion of the revisable idea that should prevent what, in research between global north and south, 
would I think be the too easy option of reaching for the non-representational where we simply do not understand, where we cannot read. Instead, what I am gesturing toward in this paper are strategies for learning and developing the literacies to move toward these singular instantiations of concept-metaphors that cannot be fully explained by those very concepts; singularities that are off our representational grid so to speak, but not by any means beyond representation in the Deleuzian sense.

\section{Decoloniality.}

In this sense, it is worth thinking with the theme of the 2017 RGS/IBG annual conference a little more concertedly: decoloniality. The Modernity/Coloniality/Decoloniality research programme has emerged principally from Latin American Studies over the last few decades. Scholars like Anibal Quijano, Maria Lugones, Walter Mignolo and others, point to the European conquest of Latin America as that which precipitated the constitution of a new world order which, half a century later, has resulted in a form of power covering more or less the whole globe: what they refer to as coloniality (Quijano 2007, p.168). In this analysis, academic knowledge production, even in its critical leftist incarnations, results in what Walter Mignolo (2002) refers to as a geopolitics of knowledge, wherein even critical leftist knowledge production is inseparable from the kind of coloniality they diagnose. In Mignolo’s (2002, p.64) words, “the planetary expansion of the social sciences implies that intellectual colonization remains in place, even if such colonization is well intended, comes from the left, and supports decolonization." What this puts to us is the very tricky double bind of, paraphrasing Audre Lord (1983), dismantling the master's house with the master's tools. 
What decolonial scholarship proposes in response to coloniality is a project of delinking knowledge production from the academy rather than scholarly transformation within the academy (Asher 2013, p.835). It looks to 'indigenous' and 'southern' thinkers for epistemic perspectives heretofore obscured by the Eurocentric rationality of Mustafa Sa'eed's library, just as it urges us to interrogate the coloniality of the ways that terms like 'indigenous', 'southern', and in the context of this journal 'tropical', fix and contain those subjects and spatialities. Decolonial scholarship suggests the very impossibility of decolonizing the academy from within, when the academy is itself the harbinger of coloniality. In other words, for decolonialists our attempts as academicians to decolonize geographical knowledge are akin to tinkering while Rome burns. And in the run up to the 2017 RGS/IBG conference and British Geography's attempt to force a conversation about decoloniality, James Esson and other members of the Race in Geography Working Group have shown us the value of reiterating that argument (see Esson et al. 2017).

As necessary as this position is, however, there are some problems with it. First, as Kiran Asher (2013, p.839) has pointed out, Mignolo and co. seem to persistently fall into the trap of equating their political aims with theory. That is to say, a kind of 'theoretical' orthodoxy has emerged around the Modernity/Coloniality/Decoloniality programme such that we end up with the intellectual object of so called decolonial praxis as theory. In other words, the argument about delinking decolonial knowledge production from the academy cannot itself be delinked from the academy and thus has problems resisting the kind of commoditization complicit with coloniality. Second, and perhaps moreover, if the Modernity/Coloniality/Decoloniality programme's trenchant insistence on delinking is to be successful, its own logic dictates that 
decoloniality ends up mitigating against the entry of subaltern, indigenous or southern thinkers into the formation of disciplinary thought or indeed public life. In fact, as the literary critic Jean Franco (2010) has observed, the eventual disintegration of the Latin American Subaltern Studies Collective was in part due to that very tension between the Latin American subaltern's potentially "generative public role" (ibid., p.222), and disagreements amongst the collective about the obstinate insistence on "not representing the subaltern within the U.S. academy" (ibid., p.214).

What this raises is a problem not of displacing the academy, but instead how to transform it, and how to transform the shape of the knowledge produced within it (Jazeel 2017). The problem is of how to bring the singularity of indigenous, southern and subaltern narratives into our imaginations in ways that, first, pluralize the very 'we' in here, and second, do so in order to (re)produce the academy as a more open, heterogenous epistemic community, or what Richa Nagar $(2014$, p.5) refers to as an "“anti-definitional' analytical space"; a space wherein those other voices are not translated out of all recognition such that they conform to our disciplinary, theoretical, and conceptual protocols. These challenges are not new. Indeed, this is the kind of decolonial epistemic politics that Wendy Shaw, Herman Douglas and Rebecca Dobbs (2006, p.272) prescribed for disciplinary Geography over 12 years ago now. As they stressed then, indigenous politics demands entirely different forms of knowledge production that are "at times, contrary to the 'geography of reason' produced during the so-called Enlightenment." This is the challenge that singularity poses, and to which I turn in the last half of this paper more directly by evoking a few methodological strategies and their potentials for routinely moving researchers toward singularity and its potential. 


\section{Singularity.}

The five brief strategies, or tactics, for moving toward singularity that I outline in what follows are not offered as a step-by-step guide in any sense. Rather, by discussing them in turn my aim is to suggest something of what singularity offers in relation to the task of bringing difference and different kinds of knowledge into representation in Anglophone geography. The strategies I discuss are: theory and reading; friction and fragments; translatability and untranslatability; abiding by; and lastly poetics. It should be clear by now that the work I want the singular to do is to ostensibly pull disciplinary Geography back from an intellectual culture of subsumption that reduces examples and cases to exchangeable instances, or conceptual givens, for the benefit of a disciplinary theory culture located in the EuroAmerican heartland (Lowrie and Ludemann 2015, p.3). Singularity stands thus as a point at which a given object is simply not defined. It should enjoin us, as researchers, to desist from what Raewyn Connell (2007, p.64) has usefully framed as a kind of "methodological projection", where "Data from the periphery are framed by concepts, debates and research strategies from the metropole."

\section{Theory and Reading}

As to the very question of 'theory' itself in Geography, our discipline has well debated its use and locatedness. Indeed feminist geography in particular has over the years sought to interrogate the performative masculinity and hegemony of Theory culture within the academy, which has precipitated a healthy suspicion amongst geographers to what Said (1983, p.239) referred to as theory's "bad infinity". This has been signalled recently, for example, in a forum recuperating Cindi Katz's (1996, 
p.489) notion of minor theory; a cluster of non-dominant perspectives that Katz intended to tear at the confining role of theories which become dominant in geography at a given time (see Jellis and Gerlach 2017). Whilst these attempts to substitute hegemonic with minor theory have pushed at the masculinity and Eurocentrism of Geography's theory culture, arguably in so doing they tend also to take the theoretical for granted. What I want to stress here is simply that Geography, and perhaps more broadly the Social Sciences, rarely stops to consider what exactly constitutes a theoretical text. In other words, to what exactly do we refer when we talk about 'theory'? What is it that distinguishes 'theory' from 'data' or 'narrative'? To this extent, it is worth stressing that the unthinking tendency in the discipline to separate and intuitively know 'theory' from 'method' is something that we have inherited from the positivist, scientific method. The Brazilian philosopher Marilena Chaui (2011, p.145) regards this unthinking approach to theoretical knowledge objects as a form of authoritarian thought, which she says "frees itself from the disturbing need to confront that which has not yet been thought." This kind of authoritarian thought, she stresses, is "Incapable of thinking difference."

To be clear, my point here is not an anti-theoretical one. Rather, I want to suggest that the discipline retreats a little from simple bifurcations of the theoretical from the empirical; from truth claims made in the absence of particular fields and contexts. The more important question as more global theoretical repertoires are built is what exactly is theory for, of what use is it, and how can it be mobilized for politicointellectual ends? In other words, not how can Geography theorize better, but why theorize better? This is to stress the 'so what?' of theory as it were. As such, these are questions that need to be directed to problem spaces located in our field contexts. In 
this respect, singularities demand a relatively undisciplined kind of disciplinary knowledge production, not in the sense of unrigorous work, but in the sense of a careful and active work that, quoting Richa Nagar (2014, p.2), "places question marks on the utility and logic of neat positions and categories", given that those very positions and categories reflect the epistemic hierarchies, logic and investments of our own locations as EuroAmerican geographers. Singularities demand to be read in their specificity, and that requires attention to historical difference.

The imperative here is to think about what can be learnt from literary, testimonial, or ethnographic narratives in and of themselves, and how that learning may in fact precipitate a useful kind of unlearning of the theoretical orthodoxies with which we are familiar and transact in the academy (see McFarlane 2006). And I use the word 'transact' deliberately because it implicates the exchange value that accompanies correct theoretical practice and written output in the political economy of the academy (Gidwani 2008, p.236). To be clear, I do not mean to suggest that Geographers are not attentive to the literary, testimonial, or ethnographic narratives they harvest from field spaces, archives and texts. Rather, I want to stress the importance of contextualizing those narratives historically, socially and culturally such that we can read from them what Raymond Williams (1977) referred to as the 'structures of feeling' to which they point. This is the work of close reading that is both radically empirical in its attention to particular and singular narratives, but at once theoretical insofar it enables a kind of correct and contextualized vision.

For example, in my own work on Buddhism and the aesthetic production of ethnicizing space and political geography in Sri Lanka (see Jazeel 2013; 2018b), this 
has entailed a decision to stand at something of a remove from the literature on the geographies of religion and post- or infra-secularism (see for example, Della Dora 2016; Kong 2001; Beaumont and Baker 2011), which I would argue ends up holding the Enlightenment concept of religion, and the sacred/secular binary woven into it, intact. In the Sri Lankan context, notwithstanding the colonial history of world religion scholarship and a late nineteenth century history of protestant Buddhism that produced and institutionalized the presence of Buddhism and its ethnicizing Sinhala power today, fragments from my fieldwork have revealed how Buddhist metaphysics also exist aesthetically in ways not reducible to the concept 'religion'. In other words, my research has found and argued that Buddhism also exists as an environmental structure of feeling, consolidated in and through certain kinds of spatialities, and told to me in terms, idioms and allegories incomparable with categorical understandings of the concept of 'religion' around which our disciplinary debates circulate.

\section{Friction and Fragments}

The intention of this briefest of examples is not to imply that singularities exist in some kind of pristine, yet impossible vacuum. It is not to essentialize the singular. Instead, it is to point to the grip of global encounter, or what Anna Tsing (2005, p.5) refers to as 'friction', which is best understood as the traction of universals as they are lived. In the context of my own research, it has been useful to think about how Buddhism thought as an institutional presence in central and southern Sri Lanka - that is to say, a discourse and colonially contrived 'world religion', in other words a 'category' - is negated as it is lived from its inside out aesthetically, intuitively, as a structure of feeling, by people who would at the same time claim to be 'secular' and thus modern. Looking for these points of friction entails, in Tsing's (ibid., p.9) words, 
a "turning away from formal abstractions to see how universals are used." She points, for example, to Celia Lowe's work on the species-collection activities of a conservation organization in the Indonesian Togean Islands, where Lowe found that English-speaking volunteers refused to learn the Indonesian names for the species they found. They saw their task instead as one of directly matching organisms found with their internationally recorded Latin species names. Their Indonesian hosts juggled local, national, and Latin species names, but in their reports only the Latin names counted (ibid., pps.94-95). What Tsing is interested in is this interpretive and epistemic moment where biological material becomes purified of its own spatial, contextual and singular histories. Friction allows her a way into following the articulative process, dipping into the cultural resources and clues she finds, and tracing their meanings closer to the ground than to their global resonances.

To this extent, Tsing's friction reveals itself in what I want to suggest are fragments, or empirical shards, embedded in fields and archives (be they material or textual). The fragment is a just as useful trope to think with in the context of singularity. In similar ways, Colin McFarlane (forthcoming a; forthcoming b) has recently speculated on exactly what fragments can help to reveal about research methodologies in the context of urban studies and urbanism. In doing so, he mobilizes a longer history of subaltern studies writings on the fragment that are useful with respect to singularity. Fragments, as McFarlane reminds us, have been fundamental to the subaltern studies project because "they present tantalizing clues to other histories and to new forms of conceptualization and methodology, often hinted at in archival research but speaking to a different way of conceiving some of the basic categories of historical investigation" (McFarlane forthcoming a, p.230). Insofar as fragments attest to 
empirical variation, they evidence new vantage points. As geographers, we might think about fragments as those traces found in field or archival work; a scrap of speech, a tract of text, a narrative, a material thing found or alluded to by a research participant perhaps. Fragments rarely make sense to our well-trained ethnographic eye or historical gaze. The fragment is thus evidence of some other whole thing, but evidence of what exactly we can rarely be sure. Drawing on Dipesh Chakrabarty, the fragment, McFarlane suggests, is a provocation that demands recognition that the world is "so plural as to be impossible of description in any one system of representation" (Chakrabarty in McFarlane forthcoming a, p.232). The fragment in this analysis, is a lure, an invitation to pause and stay with difference. Paraphrasing the anthropologist Brian Larkin (2013, p.337), the fragment leads us toward a "language to be learned", a language that is as aesthetic, atmospheric and sensorial as it is linguistic.

\section{Translation/Untranslatability}

If the fragment leads us toward a "language to be learned", it necessitates translational work. Though the relationships between translation and decolonization warrant far more discussion than is possible here, what I want to stress is not just how singularity might usher us into linguistic and ethnographic spaces of translation, but importantly spaces of untranslatability as well. For Walter Benjamin (1997 [1923], p.159), the task of the translator is to find an echo of the original in the language into which something is translated. But for Benjamin, the implication of this is that technically passable, even technically perfect, linguistic translation is never enough. It is the "incomprehensible, the secret, "the poetic"” (ibid., p.152) that good translation must veer toward. In this respect it can be useful to think of ethnographic and historical 
work as itself an act of translation insofar as it always by necessity involves the effort to learn the poetics of another form of life (see Orsini and Srivastava 2013, p.324). As much as I would want to hold to this, particularly as the time and resources for second language learning in Anglophone Geography are increasingly limited, it is important to remember that translation is about the hard work of language, of textuality, of idiom; translation is what Gayatri Spivak (1993, p.210) refers to as a most intimate act of reading, a literal act of surrendering to the text of the other.

I refer to Spivak in this context not just because she is a literary critic, but because she is a translator as well. Perhaps most famously, she has translated Jacques Derrida's $O f$ Grammatology (1976), but she has also translated the Indian Bengali fiction writer, Mahasweta Devi, whose fiction helped to bring the exploitation and neglect of Indian tribals, its Adivasi communities, into representation. Though Devi published over one hundred novels and twenty collections of short stories in Bengali, her renown in the English-speaking world has arguably been due to Spivak's translation of three of her books. In relation to the debates signaled above about the politics of delinking in relation to the Modernity/Coloniality/Decoloniality scholarship, this is a point worth underscoring. That is to say, Devi's significant influence on Anglophone understandings of the marginalization of Adivasi communities in India is as a direct result of her translation from Bengali into English. In other words, rather than delinking as such, it is precisely via the attempts to bring her into the space of the Anglophone academy and thus a broader Anglophone textual sphere (a space that Walter Mignolo might refer to as one marked by coloniality), that her own representations of subaltern narratives have been brought to the English speaking world. 
This point aside, it is Devi's story Pterodactyl, Puran Sahay, and Pirtha in the book Imaginary Maps (1995) that I want to focus on in a little more depth here. The main protagonist of the story is a journalist and caste Hindu, Puran Sahay, who travels to the fictional Pirtha Block in Madhya Pradesh, home to an Adivasi community of some 80,000 people, whose land has been devastated by the fallout from the Bhopal gas disaster in the mid-1980s. On the map, Pirtha Block is shaped like some extinct, forgotten animal, the pterodactyl no less. The community are suffering drought compounded by a contaminated water table, coupled with neglect as well as illinformed and piecemeal development initiatives that prove no practical use in the face of their hunger and the local epidemic of Enteric fever decimating the local population. In Pirtha Block, Puran Sahay's guide is an old friend, a Block Development Officer called Harisharan who introduces him to representatives from the tribal community, including a man called Shankar and a boy called Bhikia. Bikhia communicates with a pterodactyl like creature that, in the story, embodies the soul of the community's ancestors and has come back to mourn the destruction and disfiguration of their land, and indeed of the tribal community. I return to the poetics of the pterodactyl below, but for now I want to dwell on one passage in the story where Shankar, the tribal representative, is explaining to Puran Sahay and Harisharan the plight of his community:

Shankar goes on talking with his eyes closed. Alas! He speaks Hindi; Puran and Harisharan also speak Hindi, but how can one touch the other? Shankar says his say in Hindi, but the experience is a million moons old, when they did not speak Hindi. Puran thinks he doesn't know what language Shankar's 
people spoke, what they speak. There are no words in their language to explain the daily experience of the tribal in today's India. Pashupati Jonko, of the Ho tribe in Singhbhum, a native Ho speaker, had said with humble amazement at the time of translating Birsa Munda's life into the Ho language, There are no words for "exploitation" or "deprivation" in the Ho language. There was an explosion in Puran's head that day. (Devi 1995, p.118)

[Birsa Munda was a freedom fighter and tribal folk hero in the late $19^{\text {th }}$ century]

What is clear from this passage is that, as both storyteller and documentarian of Adivasi experience, for Devi these moments of untranslatability are both important and immensely productive. It is not just that this short passage reveals "exploitation" and "deprivation" to not be endemic to tribal society (in those terms). It is also that Shankar's narrative, his testimonial, is incomprehensible to Puran and Harisharan, even as Shankar speaks in Hindi, which is Puran and Harisharan's language, because as Devi's narrative emphasizes, "there are no words in their language [Hindi] to explain the daily experience of the tribal in today's India." In other words, in Hindi the ordinary contours of tribal life are unfathomable, yet for Puran it is precisely in that unfathomabilty, in his inability to grasp the tribal experience, that he sees something of the difference that inheres in tribal life when it is told on its own terms. It is in that aporetic fragment of uncommunication that an experience is communicated. Later in the story, the pterodactyl comes to stand for this difference, for the poetics of this incommunicable experience. As Puran says to his friend Harisharan, the Block Development Officer, after having come face to face with the pterodactyl: 
...There is no communication point between us and the pterodactyl. We belong to two worlds and there is no communication point. There was a message in the pterodactyl, whether it was fact or not, and we couldn't grasp it. We missed it. We suffered a great loss, yet we couldn't know it. (Devi 1995, p.195)

Devi's text shows how moments of untranslatability can, in fact, be immensely productive encounters where incommensurable differences encounter one another. Emily Apter (2013, p.3) has recently pointed to the political potential that "activating untranslatability as a theoretical fulcrum" harbours for work across the social sciences and humanities that can ethically and practically stand in opposition to what she refers to as the gargantuan scale of the Anglophonic globalization of disciplinary knowledge. Singularities, I would suggest, can reveal themselves in moments of translation failure that we need to hold on to, as Mahasweta Devi skilfully does. It is worth stressing that Spivak's translation of Pterodactyl also does this, insofar as it retains in italicized text all words that appear in English in the original. All those words that Devi cannot translate from English to Bengali are retained as material/textual traces of colonialism by Spivak's use of italicized font.

\section{Abiding by}

There is a brief postscript to Pterodactyl in which Devi writes: "I have merely tried to express my estimation, born of experience, of Indian tribal society, through the myth of the pterodactyl" (Devi 1995, p.196). What is worth teasing out from this briefest of statements is simply the time, effort and patience that Devi spent on tribal issues 
through her literary career. Singularity demands this kind of sticking with, attending to, and thus making oneself part of a particular problem space located in one's field. This is about cultivating an orientation and responsibility to the demands of a field site or area studies community, and also of treating that space as a fully formed intellectual community, not simply a data reservoir. In his work on Sri Lankan literary fiction and the civil conflict, the literary critic Qadri Ismail (2005, p.xxx) refers to this ethic as a process of 'abiding by' the places on which we work, which in turn entails the injunction to, in Ismail's words, “'wait, stay'; 'pause, delay'; 'tarry over', 'remain (after others have gone)'; 'continue'; 'sojourn...dwell'; 'to stand firm by... hold to... remain true to...'; to 'endure... encounter, withstand, or sustain'; and, finally, to 'suffer,' even."

My point here is not to suggest that as researchers we do not already try our hardest to dwell in and with the communities and places on and with which we work (see Murrey 2016, for example). Rather, it is to query just how compatible this patient attention to the singular is, where not much may change over long stretches of time, with the temporality and scale of the large grant funded research projects that promotion and reputation are increasingly dependent on in the corporate university today? The political economy of funded research in the broader para-university landscape seems to be pushing us as researchers to always scale up, to build bigger projects with ever-larger international teams and networks straddling multiple case studies over a finite period of time that is usually defined by length of funding ( 3 or 5 years is the norm). In the UK at least, universities depend financially on the 'full economic costings' that they reap in the form of revenue from these large grantfunded research projects. As such, these grants, gargantuan in scale and ambition, are 
promoted, valued, incentivized, and increasingly normalized as the kind of project to which we should aspire as researchers. Whatever else it enables, the normalization of the mega-project in the corporate university today necessarily mitigates against the patient work and effort that the ethic of sticking with, tarrying over, and abiding by over the longue duree demands. As Les Back and Shamser Sinha (2018, p.13) write in relation to their own experience of being involved in one such project, one of the effects is that researchers perennially feel "in a hurry to reach the finishing line of the next 'work package'." Similarly, there is a question mark over just how compatible the injunction to abide by is with comparative research designs, which by their very nature must spread their attention and energy over multiple case studies. What I mean to stress here are the relationships between these infrastructures for research in the academy today, particularly in the Social Sciences, and the work that the ethic of abiding by demands. At the very least, these require careful thought and working through.

\section{Poetics}

The final strategy I suggest is one to which this paper has been gesturing throughout: that is, poetics as a vehicle for moving toward the singular, the unverifiable, or the statistically insignificant. If the paper has stressed Walter Benjamin's ((1997 [1923], p.152) assertion that the task of the translator is to move readers toward what he refers to as "the poetic", then I want in closing to stress that it is in this very notion of the poetic that the singular reveals itself as some-thing. Typically, however, the poetic image does not fare so well in the Social Sciences today. In fact, in a knowledge context that privileges the frequency, visibility and verifiability of 'data', the poetic is too often pathologized, literally if we take pathologize to mean treating something as 
abnormal. The poetic is anathema to the statistically demonstrable, or to the conceptual or indeed democratic majority. In the Social Sciences, the poetic lives in the shadow of what AbdouMaliq Simone and Edgar Pieterse (2017, p.20, my emphasis) refer to as "Algorithmic formulations", which "aggregate an enormous amount of data". Instead, poetics comprise the manifold narratives of the minority, the otherwise excluded or the forgotten, marginalia, which are precisely what I want to activate by inviting the singular into our disciplinary domain, but also precisely what the Social Sciences so often legislates against in its enumerative or algorhythmic mode.

Throughout, this paper has drawn extensively on literature and literary theory, and it has done so for a very good reason. Literature tells stories, and part of my assertion is that geographers must remember that part of our task is to listen effectively to stories; not just to listen, but to learn how to read stories, particularly when they may be written or told in languages and idioms with which the majority is not familiar. To be sure, the task of Geography is also to tell the stories that our work yields in nonreductive ways. As Richa Nagar (2014, p.11) writes, stories are a medium through which fragmented truth claims emerge, get interwoven and reworked, eventually leading us to forms of epistemic wholeness. In this sense, and following Edouard Glissant's (2010 [1990], p.32) conceptualization of the Poetics of Relation, poetic thought safeguards the particular; it affords us the power to experience the shock of the elsewhere (ibid., p.29-30). I want to suggest that this cerebral electric shock of the elsewhere is exactly what decoloniality requires. For Audre Lorde (2007 [1984], p.37), another writer who celebrates the potential of the poetic image in intellectual work, poetry "is the way we help give name to the nameless so it can be thought." 
My point in relation to the literary then, is simply that it is the poetic image, the figure, that the singular offers before any theoretical or majoritarian dis-figuration. The pterodactyl in Mahasweta Devi's Pterodactyl, Puran Sahay and Pirtha is exactly such a figure; it is the ungraspable other, the nameless that emerges into thought from Devi's poetic image. As Spivak (1995, p.204) writes in her afterword to the collection:

For the modern Indian the pterodactyl is an empirical impossibility. For the modern tribal Indian the pterodactyl is the soul of the ancestors. The fiction does not judge between the registers of truth and exactitude, [it] simply stages them in separate spaces. This is not science fiction. And the pterodactyl is not a symbol.

What I think as I read Pterodactyl, Puran Sahay and Pirtha is that there is no better text to teach underdevelopment and tribal issues in northern India. In its very singularity, in its ability to help us see correctly and empathetically the contours of tribal life, the literary text becomes a valuable 'theoretical' resource. In such ways, and as I have suggested in this paper, Geography's encounters with the world can take much from the ethical singularities of the literary text.

\section{Fugitivity.}

This is a paper that has been a sketch of sorts; the beginning of a manifesto. There are no doubt many more strategies that one could discuss in the service of moving methodologically toward singularity. My hope in beginning to outline the contours of just a few here is that the paper has demonstrated something of singularity's potential 
for the task of intellectual and disciplinary decolonization in the context of a broader discussion about the theme of the 2017 RGS/IBG annual meeting: Decolonizing Geographical Knowledge: opening Geography to the world. To this extent, the thrust of this paper is well suited for the pages of this journal, which in recent history has concertedly pushed the envelope of post- and de-colonial geographical scholarship and thought. ${ }^{1}$

I do not have a conclusion to a paper that so aims to be a first few ruminations on the epistemic value of incomparability for geographical research. Rather, I have something like a last point to make. Singularity is in many ways opposed to the corporate university and para-university context today. As I have stressed, it is opposed to the gargantuan scale and global ambition of many of our institutions and the institutional contexts in which we as a community of academics work. Thus, it is difficult. In this sense, it necessitates what Stefano Harney and Fred Moten (2013, pps.25-43) refer to as a fugitive relationship to the university. It might even necessitate what they refer to as a certain kind of abuse of the university's hospitality (ibid., p.26), as a way of bringing an uncanny - meaning unhomely - quality to the university, of defamiliarising it. If the RGS and our university institutions are indeed serious about decolonization, they will tolerate this fugitivity, and embrace the imminent prospect of their own defamiliarization.

But, we must persist in our fugitivity...

\footnotetext{
${ }^{1}$ For example, see the Special Issues of the Singapore Journal of Tropical Geography on 'Geography and Postcolonialism' (2003 (24)3); 'Postcolonial Geographies of Development' (2006 (27)3); and 'Advancing Postcolonial Geography' (2014 (35)1).
} 


\section{Acknowledgements}

I would like to thank the Editorial Board of the journal for their invitation to present this lecture at the 2017 RGS/IBG Annual Meeting, and to the audience at the lecture for questions and discussion that have helped invaluably to push these thoughts on. The paper was also presented at the Unit of Play in the Sociology Department at Goldsmith's University of London, and I'm hugely grateful for the fantastically sharp comments of my discussant at the event, Sheila Sheikh, as well as those of the audience. A number of people have commented on draft versions of the paper and offered fantastically useful, insightful and thought provoking feedback. Thank you Jenny Robinson, Andrew Barry, Colin McFarlane, and especially Maite Conde. Thank you also to Tim Bunnell and Shirlena Huang for their editorial and review work on the submission. 


\section{Bibliography}

Apter, E. (2013) Against world literature: on the politics of untranslatability, Verso: London and New York

Asher, K. (2013) 'Latin American Decolonial Thought, or Making the Subaltern Speak', Geography Compass 7, pps.832-842

Back, L. and S. Sinha (2018) Migrant City, Routledge: London and New York

Beaumont, J. and C. Baker (Eds.) (2011) Postsecular Cities: space, theory and practice, Continuum: London and New York

Beauregard, R. (2003) 'City of Superlatives', City and Community 2 (3), pps.183-199

Benjamin, W. (1997 [1923]) 'The Translator's Task' (trans. Steven Rendall), TTR: traduction, terminologie, redaction 10 (2), pps.151-165

Chakrabarty, D. (2000) Provincializing Europe: postcolonial thought and historical difference, Princeton University Press: Princeton

Chauí, M. (2011) Between conformity and resistance: essays on politics, culture, and the state (translated and edited by M. Conde), Palgrave Macmillan: New York

Connell, R. (2008) Southern Theory: The Global Dynamics of Knowledge in Social Science, Allen and Unwin: Sydney

Conrad, J. (1899 [2007]) Heart of Darkness, Penguin: London

Deleuze, G. (1994) Difference and Repetition, Bloomsbury: London

Delladora, V. (2016) 'Infrasecular Geographies: making, unmaking and remaking sacred space', Progress in Human Geography 42(1), pps.44-71

Derrida, J. (1976) Of Grammatology (trans. by Gayatri C. Spivak), Johns Hopkins University Press: Baltimore

Devi, M. (1995) (trans. G. C. Spivak) Imaginary Maps, Routledge: London and New York

Dewsbury, J. D. and N. Thrift (2005) 'Genesis Eternal': After Paul Klee', in I. Buchannan and G. Lambert [Eds.], Deleuze and Space, Edinburgh University Press: Edinburgh, pps.89-108

Driver, F. and B. Yeoh (2000) 'Constructing the Tropics: Introduction', Singapore Journal of Tropical Geography 21(1), pps.1-5 
Esson, J., P. Noxolo, R. Baxter, P. Daley and M. Byron (2017) 'The 2017 RGS-IBG chair's theme: decolonising geographical knowledges, or reproducing coloniality?', Area 49 (3), pps.384-388

Franco, J. (2010) 'Moving from subalternity: indigenous women in Guatemala and Mexico', in R. Morris [Ed.], Reflections on the history of an idea: Can the subaltern speak?, Columbia University Press: New York, pps.213-226

Freiss, D. and T. Jazeel (2017) 'Unlearning "Landscape”, Annals of the Association of American Geographers 107 (1), pps.14-21

Gaston, S. (2103) The Concept of World from Kant to Derrida, Rowman and Littlefield: London

Gidwani, V. (2008) Capital Interrupted: agrarian development and the politics of work in India, Minneapolis: University of Minnesota Press

Glissant, E. (1997) The Poetics of Relation, University of Michigan Press: Ann Arbor

Harney, S. and F. Moten (2013) The Undercommons: fugitive planning and Black study, Minor Compositions: Wivenhoe, New York, Port Watson

Ismail, Q. (2005) Abiding by Sri Lanka: on peace, place and post-coloniality, University of Minnesota Press: Minneapolis

Jazeel, T. (2013) Sacred Modernity: nature, environment and the postcolonial geographies of Sri Lankan nationhood, Liverpool University Press: Liverpool

Jazeel, T. (2017) 'Mainstreaming Geography's decolonial imperative', Transactions of the Institute of British Geographers 42 (3), pps.334-337

Jazeel, T. (2018a) 'Urban Theory with an outside', Environment and Planning d: Society and Space 369(3), pps.405-419

Jazeel, T. (2018b) 'Building Sacred Modernity: Buddhism, secularism and a geography of religion in southern Sri Lanka'. in N. Bartoloni, S. MacKian and S. Pile (Eds.), Spaces of Spirituality. Routledge, London and New York. 54-66

Jellis, T. and J. Gerlach (2017) 'Micropolitics and the Minor', Environment and Planning d: Society and Space 35(4), pps.563-67

Katz, C. (1996) 'Towards minor theory', Environment and Planning d: Society and Space 14 (4), pps.487-499 
Kong, L. (2001) 'Mapping 'new' geographies of religion: politics and poetics in modernity', Progress in Human Geography 25(2), pps.211-223

Larkin, B. (2013) 'The Politics and Poetics of Infrastructure', Annual Review of Anthropology 42, pps.327-343

Lorde, A. (1983) 'The Master's Tools Will Never Dismantle the Master's House', in A. Lorde, Sister Outsider: essays and speeches, Crossing Press: Berkeley, pps.

Lowrie, M. and S. Ludemann (2015) 'Introduction', in M. Lowrie and S. Ludemann [Eds.], Exemplarity and Singularity: thinking through particulars in Philosophy, Literature and Law, Routledge: London and New York, pps.1-15

Massey, D. (2005) For Space, Sage: Los Angeles, London, New Delhi

McFarlane, C. (2006), 'Crossing Borders: development, learning and the North-South divide', Third World Quarterly 27, pps.1413-1437

McFarlane, C. (2010) 'The Comparative City: knowledge, learning, urbanism', International Journal of Urban and Regional Research 34 (4), pps.1413-37

McFarlane, C. (forthcoming a) 'Urban Fragments: a subaltern studies imagination', in T. Jazeel and S. Legg [Eds.], Subaltern Geographies: subaltern studies, space and the geographical imagination, University of Georgia Press: Athens

McFarlane, C. (forthcoming b) 'Fragment Urbanism: politics at the margins of the city', Environment and Planning d: Society and Space early on-line

Mignolo, W. D. (2002) 'The Geopolitics of Knowledge and the Colonial Difference', South Atlantic Quarterly 101 (1), pps.57-96

Mufti, A. (2005) ‘Global Comparativism’, Critical Inquiry 31, pps.472-489

Mufti, A. (2016) Forget English! Orientalisms and World Literature, Harvard University Press: Cambridge, Massachusetts

Murrey, A. (2016) 'Slow dissent and the emotional geographies of resistance', Singapore Journal of Tropical Geography 37, pps.224-248

Myers, G. (2014) 'From Expected to Unexpected Comparison: Changing the Flows of Ideas about Cities in a Post-Colonial Urban World', Singapore Journal of Tropical Geography 35(1), pps.104-118 
Nagar, R. (2014) Muddying the waters: co-authoring feminism through scholarship and activism, University of Illinois Press: Champaign

Nijman, R. (2000) 'The Paradigmatic City', Annals of the Association of American Geographers 90 (1), pps.135-45

Orsini, F. and N. Srivastava (2013) 'Translation and the postcolonial: multiple geographies, multilingual contexts', Interventions 15 (3), pps.323-331

Quijano, A. (2007) 'Coloniality and Modernity/Rationality', Cultural Studies 21 (23), pps.168-78

Robinson, J. (2006) Ordinary Cities: between modernity and development, Routledge: London and New York

Robinson, J. (2016a) 'Comparative Urbanism: New Geographies and cultures of theorising the urban', International Journal of Urban and Regional Research 40 (1), pps.187-199

Robinson, J. (2016b) 'Thinking cities through elsewhere: Comparative tactics for a more global urban studies', Progress in Human Geography 40 (1), pps.3-29

Roy, A. (2016) 'Who's afraid of postcolonial theory?', International Journal of Urban and Regional Research 40 (1), pps.200-209

Said, E. (1978) Orientalism, Penguin Books: London

Said, E. (1983) The World, the Text, and the Critic, Harvard University Press: Cambridge, Massachusetts

Salih, T. (1969) Season of Migration to the North, Heinnemann: Portsmouth

Scott, D. (2004) Conscripts of Modernity: the tragedy of colonial enlightenment, Duke University Press: Durham and London

Shaw, W., D. Herman, and R. Dobbs (2006) 'Encountering Indigeneity: re-imagining and decolonizing Geography', Geografiska Annaler b: Human Geography 88(3), pps.267-76

Simone, A. and E. Pieterse (2017) New Urban Worlds: inhabiting dissonant times, Polity: Cambridge 
Spivak, G. C. (1995) 'Afterword', in M. Devi (1995) (trans. G. C. Spivak) Imaginary Maps, Routledge: London and New York, pps.197-205

Spivak, G. C. (2003) Death of a Discipline, Columbia University Press: New York

Tsing, A. L. (2005) Friction: an ethnography of global connection, Princeton University Press: New Jersey

Wachsmith, D. (2014) 'City as ideology: reconciling the explosion of the city form with tenacity of the concept', Environment and Planning d: Society and Space 32 (1), pps.75-90

Williams, R. (1977) Marxism and literature, Oxford University Press: Oxford 